\title{
A Canadian Survey of Pharmacist Participation during Cardiopulmonary Resuscitation
}

\author{
Jennifer Bolt, William Semchuk, Peter Loewen, Ali Bell, and Caitlin Strugari
}

\begin{abstract}
Background: The participation of pharmacists on cardiopulmonary resuscitation (CPR) teams has been associated with improvements in patient outcomes secondary to lower rates of adverse drug events and higher rates of compliance with guidelines for advanced cardiac life support (ACLS). The degree to which Canadian pharmacists participate on CPR teams and the services they provide have not previously been assessed.

Objectives: To measure the frequency of pharmacists' involvement on CPR teams in Canadian health care delivery organizations, to characterize the services provided by these pharmacists, to identify positive predictors of participation, and, for health care delivery organizations without pharmacists on CPR teams, to determine the reasons for the lack of involvement.
\end{abstract}

Methods: An electronic survey was distributed to key informants in Canadian health care delivery organizations. The survey consisted of questions about characteristics of the health care delivery organizations, pharmacists' participation and role on the CPR team, training, and barriers to implementation. The primary outcome was the percentage of health care delivery organizations with pharmacists participating on CPR teams in at least one centre within the organization. The secondary outcomes were pharmacists' activities, training, and reasons for not participating on CPR teams.

Results: Forty-three of 99 key informants responded to the survey. Twenty-nine respondents (67\%) indicated that their organization had a CPR team, and $10(23 \%)$ indicated participation by pharmacists on a CPR team. Roles reported to be performed by pharmacists during CPR events were provision of drug information, preparation and administration of medications, record-keeping, and chest compressions. Training for these pharmacists was variable: ACLS training for 4 (40\%) of the 10 organizations with pharmacist participation, in-house training for 3 (30\%), and no training for $2(20 \%)$; one respondent $(10 \%)$ did not report the level of training. Reasons for not having pharmacists on CPR teams included inconsistent coverage, lack of training, and staff shortages.

Conclusions: This study characterized current pharmacist participation on CPR teams in Canadian health care delivery organizations. As evidence arises showing the impact of this practice on patient outcomes, pharmacist participation on CPR teams may become more common.

Keywords: pharmacist, cardiopulmonary resuscitation, clinical pharmacy services

Can J Hosp Pharm. 2015;68(4):290-5

\section{RÉSUMÉ}

Contexte : L'intégration des pharmaciens aux équipes de réanimation cardio-respiratoire (RCR) a été associée à une amélioration des résultats thérapeutiques, qui est due à des taux plus faibles d'événements indésirables liés aux médicaments et à un meilleur degré de conformité aux lignes directrices portant sur la technique spécialisée de réanimation cardiorespiratoire. Or, aucune étude n'a encore analysé la mesure dans laquelle les pharmaciens canadiens participent aux équipes de RCR et l'éventail des services qu'ils fournissent en leur sein.

Objectifs : Évaluer dans quelle mesure les pharmaciens participent aux équipes de RCR des organismes canadiens de prestation de soins de santé, décrire les services fournis par ces pharmaciens, identifier les facteurs prédictifs de participation et, dans les organismes de prestation de soins de santé où aucun pharmacien ne fait partie des équipes de RCR, déterminer les raisons expliquant cette absence.

Méthodes : Un sondage électronique a été donné aux informateurs clés des organismes canadiens de prestation de soins de santé. Le sondage contenait des questions portant sur les caractéristiques des organimes de prestation de soins de santé, la présence des pharmaciens au sein de l'équipe de RCR et le rôle qu'ils y jouent, leur formation en RCR et les obstacles s'opposant à leur participation. Le principal paramètre d'évaluation était le pourcentage d'organismes de prestation de soins de santé où des pharmaciens faisaient partie d'équipes de RCR dans au moins l'un des centres de l'organisme. Les paramètres d'évaluation secondaires comprenaient les activités et la formation des pharmaciens ainsi que les raisons expliquant leur absence des équipes de RCR.

Résultats : En tout, 43 des 99 informateurs clés ont répondu au sondage. Vingt-neuf répondants (67\%) ont indiqué que leur organisme avait une équipe de RCR et 10 (23\%) ont souligné la participation de pharmaciens dans l'équipe. Selon les réponses, les pharmaciens jouaient différents rôles pendant les épisodes de RCR, notamment : fournir des renseignements sur des médicaments, préparer et administrer des médicaments, effectuer la tenue de dossiers et réaliser des compressions thoraciques. La formation de ces pharmaciens était inégale : $4(40 \%)$ des 10 organismes où des pharmaciens participaient offraient une formation en technique spécialisée de réanimation cardio-respiratoire, $3(30 \%)$ offraient une formation interne et $2(20 \%)$ n'offraient aucune formation; un répondant (10\%) n'a pas précisé le niveau de formation. L'inégalité du service, le manque de formation et les pénuries de personnel faisaient partie des raisons expliquant l'absence des pharmaciens des équipes de RCR.

Conclusions : La présente étude a dressé le portrait actuel de la participation des pharmaciens dans les équipes de RCR des organismes canadiens de prestation de soins de santé. Au fur et à mesure qu’apparâtront des données illustrant l'effet de cette pratique sur les résultats thérapeutiques, il est possible que la participation de pharmaciens dans les équipes de RCR devienne de plus en plus fréquente.

Mots clés : pharmacien, réanimation cardio-respiratoire, services de pharmacie clinique 


\section{INTRODUCTION}

$\mathrm{T}$ he earliest report of a pharmacist participating on a cardiac resuscitation team was published in $1972 .{ }^{1}$ Since then, the inclusion of clinical pharmacists on organized cardiopulmonary resuscitation (CPR) teams has grown. In 1989, 25\% of surveyed US hospitals reported pharmacist participation in $\mathrm{CPR},{ }^{2}$ and this proportion increased to $37.2 \%$ by $2006 .^{3}$ In a 2005 US survey of participation in CPR by pharmacy residents, $68 \%$ of respondents reported that residents were required, or had the option, to respond as a member of the CPR team, and $86 \%$ of the formal teams included a pharmacist, ${ }^{4}$ whereas a 2009 survey by the American Society of Health-System Pharmacists found that $40.6 \%$ of hospitals had pharmacists participating on CPR teams. ${ }^{5}$ Although there are no standards dictating the role of pharmacists in resuscitation events, reported activities include provision of medication information, dosage calculation, preparation and administration of medications, documentation, operation of equipment, and chest compressions. ${ }^{4,6,7}$

The clinical benefit of pharmacist participation on CPR teams was suggested by the results of a national clinical pharmacy services survey conducted in the United States. ${ }^{3}$ The survey assessed the impact of 9 patient-specific and 6 central pharmacy services and found that 5 of the services were associated with a decrease in in-hospital mortality: managing adverse drug reactions, managing drug protocols, participating on CPR teams, participating in medical rounds, and obtaining admission drug histories. ${ }^{8}$ These findings were consistent with results from a previous survey that associated decreased in-hospital mortality with pharmacists participating on the CPR team and obtaining admission medication histories. ${ }^{9}$

The way in which pharmacists' participation in CPR events benefits patient care is unclear, but it may be due to the occurrence of fewer adverse drug events and/or better compliance with advanced cardiac life support (ACLS) guidelines. ${ }^{6,9}$ A 2008 analysis of more than 1 million medication errors found that over 2000 of the errors had occurred during hospital "code events". ${ }^{10}$ The errors reported in that study included omission of drug therapy, administration of an incorrect dose, and "unauthorized drug administration errors". Although code-related medication errors made up a small proportion of all errors in this analysis, they were 39 times more likely to result in patient harm and 51 times more likely to result in death relative to non-code-related errors. ${ }^{10}$ In a prospective observational study that assessed the rate of medication errors in medical emergency teams, ${ }^{11}$ a total of 296 medication errors occurred in 50 patients, $14 \%$ of which were potentially harmful to the patient. The errors included inappropriate prescription, preparation, labelling, and administration of medications. ${ }^{11}$

The effect of pharmacists on adverse events during CPR was assessed in a survey of 950 US hospitals. ${ }^{8}$ Sites with pharmacist participation on CPR teams had 22\% fewer adverse drug reaction reports than those without such participation. ${ }^{8}$ Data from another study demonstrated higher compliance with ACLS guidelines when pharmacists participated in CPR: noncompliance with published algorithms occurred in $31.9 \%$ of the events at which a pharmacist was present versus $59.3 \%$ of events where a pharmacist was absent. ${ }^{6}$

Despite these data, only about one-third of US hospitals have pharmacists involved in responding to CPR events. ${ }^{3}$ Reported barriers to implementation include inadequate staffing, lack of ACLS training, and lack of perception of a role for pharmacists on the team. ${ }^{6}$ It is unclear whether these experiences can be extrapolated to the Canadian context; as such, the degree to which Canadian pharmacists participate in CPR events and their roles during these events are unknown.

The objectives of this study were to measure the frequency of pharmacist involvement in CPR teams in Canadian health care delivery organizations, to characterize the services provided by pharmacists, and to identify positive predictors for participation. For health care delivery organizations without pharmacist involvement in CPR teams, the reasons for the lack of pharmacist involvement were explored from the perspective of pharmacy clinical leaders.

\section{METHODS}

\section{Design and Participants}

This survey study was approved by the Regina Qu'Appelle Health Region Research Ethics Board.

Potential participants were key informants within Canadian health care delivery organizations, defined as Canadian health authorities, health regions, local health integration networks, and individual hospitals, from each of the provinces and territories. The target population represented all health regions, health authorities, and local health integration networks in Canada. Web searches were used to identify all Canadian health care delivery organizations (a total of 79). A database of 104 key informants, including regional pharmacy directors, clinical managers, and pharmacy practice leaders, was developed from health authority and hospital staff listings, from the investigators' contacts, and by contacting the health care delivery organizations directly. Health care delivery organizations for which key informant contact information was missing (either because they had no pharmacist services or because contact information was inaccessible) were excluded.

\section{Tool}

The survey tool was drafted by the investigators, who had shared expertise in institutional pharmacy practice, survey methodology, and CPR. The survey was reviewed for face validity and content validity by CPR pharmacists, the institutional CPR steering committee (comprising physicians, respiratory therapists, and nurses), and pharmacy managers, and was edited accordingly. 
The electronically deployed survey was pilot-tested for clarity, question skip logic (with appropriate branching of later questions based on earlier responses) and face validity by the local CPR team (consisting of 2 physicians, 4 nurses, and 1 respiratory therapist) and pharmacists external to the local health care delivery organization. The questionnaire was designed and distributed using FluidSurveys (Ottawa, Ontario). The survey consisted of 20 questions in the following areas: characteristics of the participating health care delivery organizations (to facilitate identification of positive predictors), pharmacists' participation and role on the CPR team, training, and barriers to implementation. The survey was designed to take about $10 \mathrm{~min}$ to complete.

\section{Procedure}

Key informants were invited by e-mail to participate in the study. Details of the study's purpose, design, and timeline were provided, as well as a link to the electronic survey. The survey was available from April 30 to May 31, 2014, inclusive, and a reminder e-mail was sent to all prospective participants at the midpoint. Each key informant was given the opportunity to nominate a more appropriate contact to participate in the survey on his or her behalf, and the database of key informants was updated iteratively as information was received. All responses were accepted for interpretation and inclusion in the study results.

The primary outcome was the percentage of Canadian health care delivery organizations, including Canadian health authorities, health regions, and local health integration networks, that had pharmacist participation on CPR teams in at least one centre within the organization. Secondary outcomes were pharmacists' CPR-related activities and training, and reasons for pharmacists not participating on CPR teams.

No personal identifiers or sensitive information (e.g., personal health information or information that could affect employment status) was collected. At the end of the survey period, each participant was invited to submit an e-mail address (optional) to be entered to win a randomly awarded $\$ 50$ gift card for a bookstore (Amazon.ca). The e-mail addresses were not linked to study data collected.

\section{Data Analysis}

Given the categorical nature of the data, descriptive results are presented as frequency distributions. Where appropriate, cross-tabulations were used to examine differences in CPR participation by organization type and site characteristics. Organizational characteristics were assessed to identify positive predictors for CPR participation; however, the cell counts of certain organizational characteristics, such as percentage of pharmacists with advanced degree training, were too small to allow statistical exploration of differences in participation by these variables. The Pearson $\chi^{2}$ test was used to determine the statistical significance of these differences, and the Fisher exact test was used to control for small cell counts where applicable; the level of significance was set at 0.05 . All analyses were performed using SPSS Statistics for Windows, version 17.0 (released 2008; SPSS Inc, Chicago, Illinois).

\section{RESULTS}

A total of 99 key informants across Canada were invited to participate in the survey. Forty-three of these key informants responded, for a $43 \%$ response rate. Respondents were from 10 provinces; there were no responses from the territories. Characteristics of the organizations where respondents worked are summarized in Table 1. Most were multisite organizations (26/43 [60\%]) with regional coordination (16/43 [37\%]). The majority were community-based hospitals (27/43 [63\%]). Most respondents indicated that $25 \%$ or less of pharmacists at the organization were residency-trained or had advanced degree training (27/43 [63\%] and 36/43 [84\%], respectively) (Table 1). Organizations most commonly had funding for less than 10 full-time equivalent pharmacists (18/43 [42\%]) (Table 1). The survey did not ask how funded pharmacist positions were allocated within the organization. Neither the type of organization nor the hospital size was significantly related to CPR participation; however, organizations with more than $50 \%$ residency-trained pharmacists were more likely to have pharmacists participating on CPR teams $(p=0.036)$. Because of small cell counts for advanced degree training, related to a small sample size and the large proportion of respondents (39/43 [91\%]) who indicated that $50 \%$ or less of pharmacists in their respective health care delivery organizations had advanced degree training, positive prediction values for CPR participation could not be validly determined.

Twenty-nine (67\%) of the 43 respondents indicated that they were aware of a CPR team within their organization. Nonpharmacist members of the team included registered nurses, respiratory therapists, trainees, intensivists, and "other" disciplines. For 4 CPR teams, pharmacists were mentioned in the "other" category, along with emergency department physicians, other specialized or generalized physicians, and specialized critical care nurses.

Of the 43 respondents, $10(23 \%)$ indicated that pharmacists were a part of the CPR team in at least one site within the organization. Training for these pharmacists was variable: ACLS training for 4 (40\%) of the 10 organizations with pharmacist participation, in-house training for $3(30 \%)$, and no training for $2(20 \%)$; one respondent (10\%) did not report the level of training (Table 2). The 2 most common pharmacist activities within CPR teams were providing drug information and preparing medications, followed by administering medications, recordkeeping, and performing chest compressions (Table 2). Pharmacists primarily responded to events Monday to Friday (6/10 [60\%]). Respondents for 2 organizations (20\%) reported coverage 7 days per week: for one organization, coverage was available during the critical care pharmacist's working hours, and 
This single copy is for your personal, non-commercial use only.

For permission to reprint multiple copies or to order presentation-ready copies for distribution, contact CJHP at cjhpedit@cshp.ca

Table 1. Characteristics of Health Care Delivery Organizations Represented by Survey Respondents

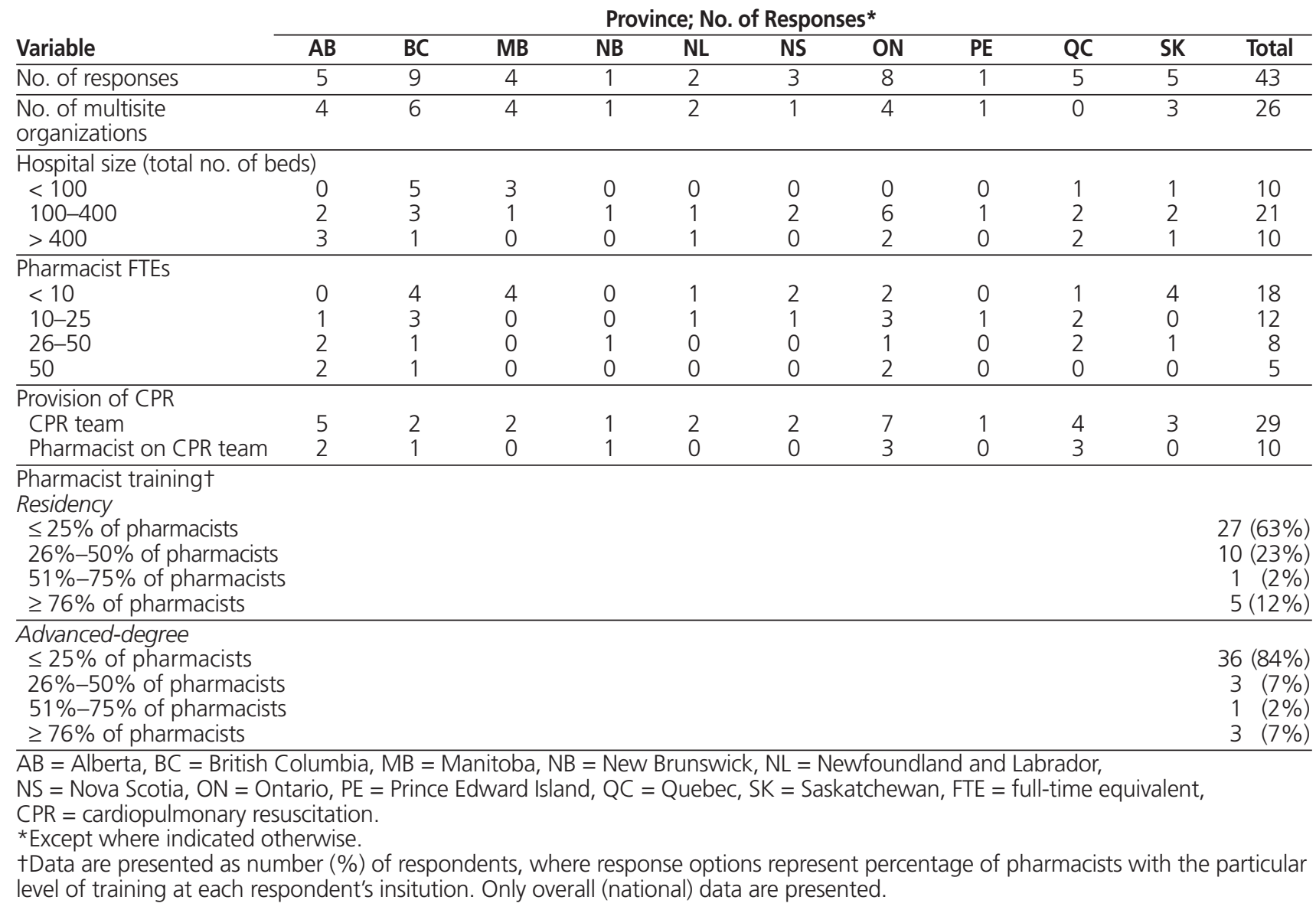

\section{Table 2. Primary and Secondary Outcomes for Pharmacists Participating in CPR}

Outcome

No. (\%) of Respondents

\begin{tabular}{lcc}
\hline Primary outcome: Pharmacist & 10 & $(23)$ \\
participation on CPR teams $(n=43)$ & & \\
\hline Secondary outcomes & & \\
Pharmacist activities in CPR $(n=10)$ & & $(90)$ \\
Providing drug information & 8 & $(80)$ \\
Preparing medications & 3 & $(30)$ \\
Administering medications & 2 & $(20)$ \\
Record-keeping & 2 & $(20)$ \\
Chest compressions & 4 & $(40)$ \\
Pharmacist training for CPR teams $(n=10)$ & \\
ACLS training & 3 & $(30)$ \\
In-house training & 2 & $(20)$ \\
No training & 1 & $(10)$ \\
No response & \multicolumn{2}{c}{ (10) } \\
ACLS = advanced cardiac life support, CPR = cardiopulmonary \\
resuscitation.
\end{tabular}

for the other organization, coverage was available when a pharmacist was on shift in the intensive care unit or the emergency department. Most respondents (8/10 [80\%]) indicated that a single pharmacy staff member participated on the CPR team, whereas 2 respondents (20\%) indicated that 2 pharmacy staff members participated.

The most commonly reported reasons for no pharmacist participation on CPR teams were inconsistent coverage and lack of training, followed by staffing shortage, lack of support, and "other" (Table 3). Free-text responses indicated competing clinical foci, lack of awareness of the benefits for patient outcomes, and not a priority for other reasons.

\section{DISCUSSION}

To the authors' knowledge, this is the first survey of the Canadian landscape of pharmacist involvement in CPR. The frequency of involvement of pharmacists on CPR teams (23\%) was less than that reported in the United States. ${ }^{3,5}$ However, such comparisons should be made with caution, because of differences in the study populations (health care delivery organizations in the current study versus hospitals in the previous studies) and a suboptimal response rate in the current study.

Pharmacists' primary role on CPR teams was provision of medication information and preparation of medications for administration, a finding similar to those of previously published studies. ${ }^{4-6,11-14}$ Previous studies have reported activities such as 
This single copy is for your personal, non-commercial use only.

For permission to reprint multiple copies or to order presentation-ready copies for distribution, contact CJHP at cjhpedit@cshp.ca

Table 3. Reasons for Not Having Pharmacists Participate on CPR Teams

\section{Reason}

Inconsistent coverage

Lack of training

Staffing shortage

Lack of support

Other*

$\mathrm{CPR}=$ cardiopulmonary resuscitation

*Other responses were" competing clinical foci"; "lack of support from pharmacy management"; "not aware of a clear evidence to support the outcomes for patients given the rates are poor to begin with"; "this has not been prioritized as function of our department and inconsistent coverage would be one of several reasons why it has not been"; "we do have two pharmacists who sit on our Code Blue Committee, who are able to give input at that level"; and "we have one pharmacist ... in ER [emergency]/critical care and we want to make a project with him in a [CPR] team."

calculating drug dosages, making drug therapy recommendations, and screening for drug interactions or allergies. ${ }^{5,6,12,13}$ Although those activities were not specifically assessed in the current study, they may be considered as belonging within the category of provision of drug information.

Residency-trained pharmacists and pharmacists with advanced degree training did not account for the majority of pharmacists responding to code situations at the health care delivery organizations represented by survey respondents. Most respondents indicated that $25 \%$ or fewer pharmacists had advanced training; 5 institutions had $76 \%$ or more residencytrained pharmacists, and only 3 had $76 \%$ or more advanced degree-trained pharmacists. A correlation between presence of residency-trained pharmacists and participation in CPR was observed, but a correlation for advanced degree-trained pharmacists could not be assessed because of small sample size. The associations between pharmacist participation and presence of residencytrained pharmacists can be related to a study of pharmacy resident participation in $\mathrm{CPR}$ events, ${ }^{4}$ in which the rate of participation was higher than reported by other researchers. The authors concluded that this higher rate might have been due to the nature of the study population (organizations with established residency programs, which might have had more resources for clinical pharmacy services); alternatively, the study's respondents (pharmacy residency directors) might have been trained at institutions where CPR participation was required, which might in turn have led them to incorporate CPR into their own current training practices. ${ }^{4}$ Furthermore, some centres in the United States now include ACLS certification as a requirement for completion of a residency. ${ }^{4}$ Implementing a program like ACLS training into residency programs or pharmacist staff training in Canada might increase the involvement of pharmacists on CPR teams in this country.

Lack of training was seen as a barrier to pharmacist participation in CPR in this survey, as well as in one previous US survey. ${ }^{12}$ Among the centres that did have pharmacist participation in CPR, training varied, with the majority of respondents reporting either formal ACLS certification or in-house training of pharmacists. Appropriate training is important to give pharmacists the competence and confidence necessary to be a valuable member of the CPR team. ${ }^{12}$ Training may also improve the perception of the pharmacist's role on CPR teams. Programs available for training include basic life support (BLS), ACLS, and pediatric advanced life support. ${ }^{4,12,13}$ In the United States, some institutions require all pharmacists to have ACLS and/or BLS certification, regardless of whether the pharmacists will participate in CPR, whereas other institutions offer such training as an option..$^{4,12,13}$ One centre in Michigan developed a modified training program that accommodated its pharmacy department's needs, including more pharmacotherapeutic education, in addition to the required ACLS and BLS training. The results of a pilot study showed increased compliance with ACLS guidelines after initiation of the program, as well as increased pharmacist comfort. $^{12}$

Inconsistent coverage was also identified as a barrier in the current survey. This situation is not unique to Canadian institutions. ${ }^{12}$ It may be in part a result of CPR team participation being a lower priority within the clinical services plan for pharmacy departments. Clinical pharmacy services are a relatively new concept for pharmacy practice, and the acceptance and institution of these roles, as well as the policies to support them, require persistence and clear benefits. Surveys such as this one, along with additional studies demonstrating improved patient outcomes, may aid in the expansion of this clinical pharmacy practice.

Finally, staffing shortages were identified as a potential barrier to pharmacist participation on CPR teams. The development of policies to ensure cross-coverage or the utilization of specific ward pharmacists (e.g., critical care or emergency pharmacists) ${ }^{14}$ may be ways to overcome this barrier.

This survey has established a baseline for pharmacist participation on CPR teams in Canada and has identified pharmacists' roles in CPR and barriers to such participation. Organizational leaders and managers may use information such as this to aid in allocation of resources. The Hospital Pharmacy in Canada Survey provides benchmarking for other clinical pharmacy services, but does not cover CPR participation. ${ }^{15}$ This may be an area of interest for inclusion in future Hospital Pharmacy in Canada Surveys.

Future research is required to identify the frequency of pharmacist participation on CPR teams within individual hospitals (as opposed to multisite organizations), as was done in the US studies. This type of data may allow for more accurate representation of uptake or support for this clinical practice and may allow direct comparisons between US and Canadian practices. Further assessment of the clinical benefit of pharmacist participation in CPR is needed to better appreciate the impact of this practice on patient outcomes and to add to existing 
evidence. Additional research could also include assessing the impact of pharmacist coverage on pharmacist participation on CPR teams, identifying the number of pharmacists within an organization that participate on CPR teams, and studying a large enough sample to accurately identify multiple positive predictors of participation.

This study had several limitations. First, the number of respondents indicating that their organization had a pharmacist on CPR teams was only 10 , a sample size that may be too small to draw any clinically meaningful conclusions for the types of activities that these pharmacists perform. In 2 provinces, the number of surveys returned was one more than the number distributed. This discrepancy may have resulted from the main contact forwarding the link to the electronic survey to other key individuals within the organization. A misclassification error may have occurred, as one respondent indicated uncertainty as to whether a pharmacist was on the institution's CPR team, but later indicated that this pharmacist had received ACLS training to participate in CPR; the "unsure" response was reallocated to the "yes" category for interpretation of the results. A fourth limitation was potential selection bias. For some organizations, the investigators did not have contact information for key informants, and these authorities were not represented in the study. As well, some invited participants did not complete the survey. Individuals who were more interested in or currently participating in this pharmacist practice may have been more likely to respond to the survey. Finally, the survey asked whether pharmacists participated on CPR teams in at least one institution within the health care organization. Given that many health authorities have multiple facilities within their respective organizations, the calculated percentage may have been an overestimation. These results may not be representative of the true participation of pharmacists on CPR teams in Canadian hospitals and may be misleading. Furthermore, it is difficult to make meaningful comparisons with other studies that looked at the rate of participation per hospital rather than per health region.

\section{CONCLUSIONS}

To the authors' knowledge, this is the first study to assess the frequency of pharmacist participation in CPR in Canadian health care delivery organizations. The primary roles of pharmacists during CPR events were providing drug information and preparing medications. Further research is required to assess the impact of this practice on patient outcomes. As this evidence arises, pharmacist participation on CPR teams may become more common.

\section{References}

1. Elenbaas R. Pharmacist on resuscitation team. NEnglJ Med. 1972;287(3):151.

2. Raehl CL, Bond CA, Pitterle ME. Pharmaceutical services in U.S. hospitals in 1989. Am J Health Syst Pharm. 1992;49(2):323-46.

3. Bond CA, Raehl CL. 2006 national clinical pharmacy services survey: clinical pharmacy services, collaborative drug management, medication errors, and pharmacy technology. Pharmacotherapy. 2008;28(1):1-13.
4. Toma MB, Winstead PS, Smith KM, Lewis DA, Clifford TM. Pharmacy resident participation in cardiopulmonary resuscitation events. Am J Health Syst Pharm. 2007;64(7):747-53.

5. Pedersen CA, Schneider PJ, Scheckelhoff DJ. ASHP national survey of pharmacy practice in hospital settings: monitoring and patient education2009. Am J Health Syst Pharm. 2010;67(7):542-58.

6. Draper HM, Eppert JA. Association of pharmacist presence on compliance with advanced cardiac life support guidelines during in-hospital cardiac arrest. Ann Pharmacother. 2008;42(4):469-74.

7. Shimp LA, Mason NA, Toedter NM, Atwater CB, Gorenflow DW. Pharmacist participation in cardiopulmonary resuscitation. Am J Health Syst Pharm. 1995;52(9):980-4.

8. Bond CA, Raehl CL. Clinical pharmacy services, pharmacy staffing, and adverse drug reactions in United States hospitals. Pharmacotherapy. 2006; 26(6):735-47.

9. Bond CA, Raehl CL, Franke T. Clinical pharmacy services and hospital mortality rates. Pharmacotherapy. 1999;19(5):556-64.

10. Lipshutz AK, Morloc LL, Shore AD, Hicks RW, Dy SM, Pronovost PJ, et al. Medication errors associated with code situations in U.S. hospitals: direct and collateral damage. Jt Comm J Qual Patient Saf. 2008;34(1):46-56, 1.

11. Gokhman R, Seybert AL, Phrampus P, Darby J, Kane-Gill SL. Medication errors during medical emergencies in a large, tertiary care, academic medical center. Resuscitation. 2012;83(4):482-7.

12. Hashemipour Z, Delgado G Jr, Dehoorne-Smith M, Edwin SB. Pharmacist integration into cardiac arrest response teams. Am J Health Syst Pharm. 2013;70(8):662,664,666-7.

13. Bembea MM, Rapan Parbuoni KA, Zimmer KP, Veltri MA, Shilkofski NA, McMillan-Nelson K, et al. Characteristics of medication use during pediatric medical emergency team events and the role of a pharmacist-provided medication supply. J Pediatr Pharmacol Ther. 2012;17(3):236-45.

14. Jurado LV, Steelman JD. The role of the pharmacist in the intensive care unit. Crit Care Nurs Q. 2013;36(4):407-14.

15. Hospital Pharmacy in Canada Editorial Board. Hospital pharmacy in Canada 2011/2012 report. Eli Lilly Canada; 2013. 107 p. Available from: www.lillyhospitalsurvey.ca/hpc2/content/2012_report/FULL-2012.pdf

Jennifer Bolt, BSCPharm, ACPR, PharmD, is Residency and Education Coordinator, Department of Pharmacy Services, Regina Qu'Appelle Health Region, Regina, Saskatchewan.

William Semchuk, MSc, PharmD, FCSHP, is Manager of Clinical Pharmacy Services, Department of Pharmacy Services, Regina Qu'Appelle Health Region, Regina, Saskatchewan.

Peter Loewen, BSC(Pharm), ACPR, PharmD, FCSHP, RPh, is Director of Doctor of Pharmacy Programs and Assistant Professor, Faculty of Pharmaceutical Sciences, The University of British Columbia; Pharmacotherapeutic Specialist (Medicine), Vancouver General Hospital; and Chair, UBC Clinical Research Ethics Board, Vancouver, British Columbia.

Ali Bell, MA, MSc, is a Research Scientist, Department of Research and Health Information Services, Regina Qu'Appelle Health Region, Regina, Saskatchewan.

Caitlin Strugari, BSP, ACPR, was, at the time of the study, a Pharmacy Resident with the Regina Qu'Appelle Health Region, Regina, Saskatchewan. She is now a Pharmacist, Department of Pharmacy Services, in the same organization.

Competing interests: None declared.

\section{Address correspondence to:}

Dr Jennifer Bolt

Department of Pharmacy Services

Regina Qu'Appelle Health Region

1440 - 14th Avenue

Regina SK S4P OW5

e-mail: jennifer.bolt@rqhealth.ca

Acknowledgements: The authors thank Julia Higgins, MSc, a pharmacy student in the Faculty of Pharmaceutical Sciences, The University of British Columbia, for developing the database of participants used in this study.

Funding: None received. 